\title{
О двух бродячих словах восточного происхождения в древнерусском языке
}

\author{
KLÁRA AGYAGÁSI \\ Debreceni Egyetem BTK Szlavisztikai Intézet, H-4032 Debrecen, Egyetem tér 1. \\ Institute of Slavic Studies, Faculty of Humanities, University of Debrecen \\ E-mail: agyagasi.klara@arts.unideb.hu
}

(Received: 4 January 2018; accepted: 22 March 2018)

\begin{abstract}
The author presents a historical-etymological analysis of two Russian words kunžut 'sesame' and xamovnik 'weaver'. According to her argumentation, Russian kunžut has Tokharian origin, it was borrowed from Tokharian A by Old Uygur before the 12th century. From Old Uygur, it was intermediated by Middle Mongol and Middle Kipchak to Russian. Xam, the stem of xamovnik is preserved in one of the Old Novgorodian birk barch letter from the beginning of the 14th century. It was borrowed from the Cantonese dialect of the Chinese language by West Old Turkic, and a West Old Turkic form was borrowed by Old Russian.

Keywords: Russian vocabulary, oriental elements, Middle Kipchak loanwords, West Old Turkic loanwords, Chinese loanwords, Middle Mongolian intermediation
\end{abstract}

Исследование лексики восточного происхождения в русской этимологической литературе началось в первой половине XIX века (обзор литературы с самых начал до 1970 г. см. Менгес 1970, ДоБРодомов-РомАновА 1970, а более свежих исследований см. AgYAGÁsI 2016). В большинстве ранних трудов главной задачей исторических разысканий являлось определение окончательного источника древних восточных заимствований, при этом не обращалось внимание на то, что нередко географические или хронологические условия не позволяли предположение непосредственного контактирования русского языка с окончательным источником.

Ниже будут представлены два образца историко-этимологического анализа бродячих слов восточного происхождения, особый акцент при этом ставится на промежуточные фазы их странствования с помощью реконструкций на основании историко-сопоставительного метода.

Кунжут 'растение Sesamum’ (Даль 2: 218).

Исследование слова, как это отмечается Е. Н. Шиповой, началось в русской этимологической литературе с появления двухтомного словаря П. Соколова в 1834 г. (Соколов 1834, ШиповА 1976: 209). По мнению Соколова, этот ботанический термин имеет персидское происхождение (пер. kunjud). Его мнение господствовало в русском языкознании вплоть до середины XX века. М. Фасмер на основании записи В. В. Радлова возводит слово к уйгурскому künjit 'сезам' (РАдлов 1899: 1446, VASMER 1953: 694). Но ни русские 
исследователи, ни Фасмер не поднимают вопрос о том, когда и где было заимствовано данное слово русским языком, каким образом было возможно заимствование слов между непосредственно неконтактирующими языками. Шипова приводит параллели уйгурского слова из некоторых тюркских языков, ср. кирг. künžüt (КргРСл), узб. kunžut (УРСл), азерб. künčüt 'кунжут’ к ним можно еще добавить казах. künžit (КазкРСл) и казанско-татарское kӧnjět (ТРСл) в том же значении, - но о подробности процесса заимствования она не высказывает свое мнение (Шипова 1976: 209).

Географическое распространение слова (от Средней Азии до России в широком кругу тюркских и персидских языков) обосновывает предположение о бродячем характере ${ }^{1}$ изучаемого слова. На его окончательное происхождение удалось указать Дж. Клосону: др.-тюрк. künčit 'sesame (seed)', сохраненное в буддийских текстах уйгурских письменных памятников, является заимствованием формы kuñ čit из тохарского А языка (CLAUSON 1972: 727-728). Клосон одновременно высказывает предположение еще о том, что тохарское слово является в русском языке ранним заимствованием из одного из - ближе неопределенных - тюркских языков. Кроме цитированных Клосоном древнетюркских памятников, форма künčit 'кунжут' обнаруживается еще в древнеуйгурских юридических документах XII-XIV веков (ДТС 327) и в уйгурских источниках медицинского содержания (RACHмATI 1932: 401448). Все это значит, что тохарское слово заимствовалось непосредственно уйгурским вариантом восточно-древнетюркского языка при непосредственном сопрокосновении тохарского и древнеуйгурского языков и их носителей. Изучая тохарские заимствования в алтайских языках, А. Рона-Таш установил, что тохарские заимствования в тюркских языках имеют два хронологических пласта: в первый входят те лексические элементы, которые были заимствованы из пратохарского пратюркским, а во второй пласт входят те слова из тохарского А и Б, которые перешли в древнеуйгурский язык, и оттуда - в среднемонгольский (RÓNA-TAS 1986: 71-72).

Тохарское слово kuñ čit из тохарского А могло попасть в древнеуйгурский в форме künčit 'кунжут', соблюдая правила тюркского сингармонизма. После основания монгольской империи в XIII веке и завоевания ею восточных территорий в сторону Китая, монголы заимствовали много элементов уйгурской культуры: предметы разного назначения и их названия, и даже уйгурское письмо, ставшее впоследствии одной из монгольских национальных письменных систем. Древнеуйгурское слово künčit, называющее неизвестное монголам растение, тоже было заимствовано монголами в среднемонгольский период. Об этом свидетельствует современный монгольский

${ }^{1}$ Предположение о том, что мы имеем дело с бродячим словом, подтверждается еще и тем, что - кроме приведенных данных - существует и другой фонетический вариант слова, распространенный в разных тюркских языках: ср. тур. künсӥ ‘кунжут’ (ТурРСл), туркм. künji (ТуркмРСл), кк. günži (РКпкСл) 'то же’. Ш. Акалин считает этот вариант заимствованием из одного из персидских диалектов (AKALIN 2011: 1560). Изучение возникновения и распространения этого варианта слова не входит в наши задачи. 
язык, словарный запас которого фиксирован и уйгуро-монгольским письмом (cp. Lessing 1973), и кириллическим (ср. BAWDEN 1996, KARA 1998). Исследуемое слово у Ф. Лессинга встречается (в транскрипции на латинское письмо) как gynzid, kynzid 'Sesame' (LeSsING 1973: 391, 503), а в словаре Ч. Баудена и Д. Кары как гүнжид 'Sesame’ (BAwDEN 1996: 105, KARA 1998: 119). Среднемонгольская форма слова реконструируется как *künǰid. Она могла распространяться из среднемонгольского языка в среднекыпчакские диалекты (они бытовали на бывшей территории государственных образований джингисидов) и сохранилась в современном киргизском, казахском и казанско-татарском языках. Фонетический облик современного казанско-татарского слова (könjět) указывает на релятивную хронологию заимствования слова: форма *künjid попала в среднекыпчакский язык как *künǰit до начала процесса редуцирования гласных верхнего подъема (см. ТумАшеВА 1989), и ее гласные фонемы участвовали в системном изменении гласных фонем татарского языка: *künǰit > kö̈njęt. ${ }^{2}$ Во многих среднекыпчакских диалектах произошла ассимиляция второго гласного первому по огубленности. Такое уподобление налицо и в киргизской форме слова (см. выше). Но то же самое изменение могло происходить и в предшественнике казанско-татарского языка в изучаемом слове: *künjit $>$ *künǰüt. В современном татарском языке по общему правилу редуцированный гласный второго слога после огубленного редуцированного в первом произносится тоже огубленным (см. КурБАтов 1995: 121), только современная орфография не обозначает лабиальную гармонию гласных непервого слога. Это значит, что современная татарская форма könjе̌t

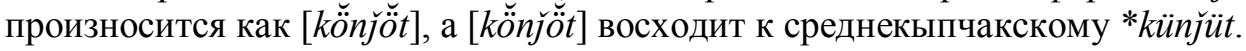

Осталось только ответить на тот вопрос, как произошло непосредственное заимствование среднекыпчакского слова русским. Важно отметить, что русское название растения Sesamum в письменных памятниках и народных говорах русского языка не сохранилось. Даже фонетический облик русского слова не дает сведений о том, какой из разновидностей великорусского языка было заимствовано слово. Звуковое оформление слова свидетельствует только о том, что русские заимствовали среднекыпчакскую форму с огубленными первым и вторым гласными. ${ }^{3}$ Сведения древнетюркских памятников объясняют значение этого растения для тюркских народов: из семян кунжута добывали кунжутное масло, которое было в применении как лечебное средство. Все это дает основание предполагать, что кунжут являлся товаром, которым торговали предшественники татар, а покупателями могли быть члены узкой элиты русских княжеств, с которыми татары имели постоянные связи с XIII века (об их исторических отношениях см. VÁsÁRY 2007, VÁsÁRY 2015).

\footnotetext{
2 Такое изменение (редуцирование узких и сужение широких гласных) характеризует все другие среднемонгольские заимствования казанско-татарского языка (сp. RÓNA-TAS 1982).

${ }_{3}^{3}$ Научная разработка среднекыпчакских заимствований в русском языке пока не проведена. Е. Н. Шипова собрала большое количество тюркизмов в русском языке, но регулярное разграничение источника единичных заимствований на основании фонетических критериев разных кыпчакских языков видится неосуществимым и в настоящее время (см. ШипОВА 1976).
} 
Суммируя результаты исследования истории слова, можно реконструировать путь его распространения от тохарского до русского следующим образом: тохарск. А kuñčit 'Sesame' $\rightarrow$ др.-уйг. künčit $\rightarrow$ cp.-монг. *künjid $\rightarrow$ ср.-кыпч. *künjit > *künjüt $\rightarrow$ cp.-pyc. kunžut 'то же'.

Хамовник 'ткач, полотнянщик, скатертник' (ДАль 4: 542).

Русское слово относится к устаревшему слою русской лексики. Оно является термином ремесленной промышленности, называет мастера, изготавливающего полотна, полотенца и скатерти, и является производным образованием: $x a м+o в+н и к$. Слово к настоящему времени сохранилось только в названии района города Москвы Хамовники, и уже никто не может сказать, на каком основании отождествляется корень слова $х а м$ с полотенцами и скатертями.

Слово $х а м$ в корневой форме ${ }^{4}$ встречается в древненовгородском диалекте (xaMz), оно зафиксировано на берестяной грамоте, датированной 20-ми и 30-ми годами XIV века (см. грамоту № 288 - ЗАлизняк 2004: 541). А. А. Зализняк толкует его как 'полотно'. Однако, как на это правильно указывает К. Ковач, сам текст цитированной грамоты (в котором перечисляются разные сорта купленных ткачом драгоценных текстильных материалов) вносит в значение этого слова коннотацию 'дорогой текстильный товар' (KovÁCs 2016: 25).

В связи с происхождением этого слова Фасмер только указывает на попытки финских ученых связать русское слово с финскими и германским параллелями (ср. фин. hame 'юбка', эст. hameh, hame 'рубаха', др.-исл. hamr 'оболочка', гот. gahamôn 'одевать'), но их связь с русским словом он считает не достоверной (ФАСМЕР 3: 221).

Надежную основу для установления этимологии русского слова представляет фрагмент восточно-древнетюркского источника XII-XIV вв. на уйгурском письме, содержащий слово qатqї ‘камка, шелковая материя’ (ДТС 416). Западно-древнетюркский вариант этого слова в письменных памятниках не сохранился, но его фонетическая реконструкция не представляет трудности на основании прочих источников западно-древнетюркского языка. В западнодревнетюркском диалекте спирантизация заднего $q$ в $x$ в абсолютном начале слова началась в VII веке, как об этом свидетельствует написание монограммы на перстне с печаткой булгарского кагана Куврата (hovratou), найденном в его могиле (см. WERNER 1984, RóNA-TAS 1996: 180-181). А задний $q$ в инлаутном и ауслаутном положении прежде озвончался, потом исчез через спиранта $(q>\dot{g}>\gamma>\varnothing)$ на значительной части западно-древнетюркского языкового пространства до IX века. На это указывают некоторые западно-древнетюркские заимствования в русском и венгерском языках: зап.-др.-тюрк.,

\footnotetext{
${ }^{4}$ Его производная форма как отыменное прилагательное (хамиямыи) записана в источнике «Явка сельскаго прикащика Второго Васильева и разныхъ крестянъ» из 1579 года (см. СРЕЗНЕВСКИЙ 3: 1359).
} 
волжско-булг. buraq 'beer' > *burag $>* b u r a \gamma \rightarrow$ др.-pус. bbraga 'то же' (см.

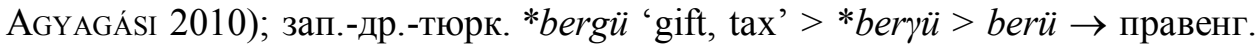
berü > венг. bér 'то же' (см. RÓNA-TAS-BERTA 2011: 115-118). Соответственно этому, западно-древнетюркская форма восточно-древнетюркского слова реконструируется как * $\chi a m \ddot{~}(<* \chi a m \gamma \ddot{i}<$ qamqi). Она заимствовалась древненовгородским диалектом до падения редуцированных. ${ }^{5}$ Последний гласный -ї тюркской формы не мог сохраниться в древнерусском варианте слова по морфологической причине. Изучаемое существительное должно было адаптироваться в систему древнерусского именного склонения, но древнерусский язык не имел основ на твердый гласный -ї в своей системе. По свидетельству цитированной берестяной грамоты, после заимствования западно-древнетюркское слово на древнерусской почве уподобилось существительным мужского рода с основой на $-\breve{u}$, так как фигурировало оно в указанной грамоте в родительном падеже с окончанием -y. Гласный -ї был субституирован через - $b$ (звучащий как редуцированный заднего ряда), и слово в древненовгородском диалекте приобрело форму хамz. Оно, по всей вероятности, сохранило первоначальное значение 'камка, шелковая материя', зафиксированное в восточно-древнетюркском памятнике.

Возникает вопрос о том, откуда попало это слово в диалекты древнетюркского языка, ведь тюрки-кочевники не занимались ремеслами, они не производили драгоценные текстильные материалы. Соответственно, и древнетюркское существительное не имеет тюркскую этимологию.

Древнетюркское слово имеет китайское происхождение. Но установить китайскую донорную форму уже долгое время оказывается очень трудной задачей, так как это существительное является бродячим словом, имеющим несколько фонетических вариантов в разных языках $(\operatorname{kim}[a], \operatorname{kim}[a b], \operatorname{kam}[a]$, kam[ab], camoca, сатисca, camucan - подробнее см. AgYAGÁsı 2016: 392-393). Как на это указывает Г. Дёрфер, начиная с IX века слово распространилось во множестве азиатских языков (см. DOERFER 1967: 604-605), а после поездки Марко Поло в Китай это название специальных тканей появилось и в целом ряде европейских языков (см. РELLIOT 1959: 145-146). П. Пеллио рассмотрел синологическую литературу относительно происхождения китайских слов co значением 'damask, brocade, silk', и после длительной дискуссии маловероятных этимологических толкований разных авторов он принял мнение Й. Юла в качестве самого вероятного. Соответственно этому, ближе ко всем формам, которые были распространены в языках Евразии, стоит китайское выражение chin-hua (<*kiəm- $\left.\chi^{w} a\right)$, которое имело значение 'золотой цветок'. Но c IX века это выражение прошло ряд семантических изменений и стало обозначать те разновидности узорчатых тканей, которые имели золотые цветки как узор материала. Китайское слово в южнокитайских диалектах имело

5 Древний Новгород - как пишет об этом В. Л. Янин - был расположен на пересечении торговых путей с востока на запад и с юга на север, и являлся крупным торговым центром с XI по XIV вв. (Янин 2008: 21). 
произношение как kimh hāw (PELLIOT 1959: 149-150), откуда было заимствовано арабскими и персидскими торговцами и опосредовано разными языками по шелковому пути. Но в кантонском произношении первая часть сложного слова звучала как kam, в этой форме его могли заимствовать торговцы из других стран, среди них древние тюрки обоих диалектов. ${ }^{6}$ Двоякость китайской донорной формы объясняет фонетическое различие древнетюркских и арабских (также персидских) форм, а в других языках звучание слова изменилось благодаря опосредованию. Относительно происхождения русской и турецкой форм китайского слова Пеллио и Дёрфер предполагали персидское опосредование. Но им был еще не известен тот содержащий слово восточнодревнетюркский источник XII-XIV вв., о котором было упомянуто в «Древнетюркском словаре», вышедшем спустя десять лет после опубликования исследования Пеллио.

Суммируя вышесказанное относительно происхождения русского слова хамовник 'ткач, полотнянщик, скатертник', можно прийти к следующим выводам.

Корнем производного слова является существительное хам- 'узорчатая ткань', которое было заимствовано в древнерусский период древненовгородским диалектом до падения там редуцированных гласных. Слово является бродячим словом, окончательно восходящим к китайскому оригиналу. Оно распространялось разными путями в языках Евразии с IX по XIV вв. Его появление в русском языке реконструируется следующим образом: кит. *kįm$\chi^{w} a$ 'золотой цветок' > кантонск. диал. кит. языка $k a m h \bar{a} w \rightarrow$ зап.-др.-тюрк. * $\chi а т \gamma \ddot{i}>\chi а т і ̈ \rightarrow$ др.-новг. диал. хамъ 'узорчатая ткань'.

Образование древненовгородского корня могло происходить с середины XIV века при помощи суффиксов -ов- и -ник славянского происхождения.

\section{Словари}

Даль = ДАль В. И. Толковый словарь живого великорусского языка. Т. 1-4. Москва, 1989.

ДРС = Словарь русского языка XI-XVII вв. Вып. 1-28. Москва, 1975-2008.

ДТС = НАДЕЛЯЕВ В. М., НАСИЛОВ Д. М., ТЕНИшЕВ Э. Р., ЩЕРБАК А. М. (ред.) Древнетюркский словарь. Ленинград, 1969.

КазКРСл = МАХмУДОВ Х., МУСАБАЕВ Г. (ред.) Казахско-русский словарь. Алма-Ата, 1959.

КргРСл = ЮдАхин К. К. (ред.) Киргизско-русский словарь. Москва, 1965.

\footnotetext{
${ }^{6}$ Китайское слово появилось также в русском и через опосредования восточно-древнерусского диалекта (ср. вост.-др.-тюрк. qamqї $\rightarrow$ др.-рус. kamka), но в этом случае субституция древнетюркского конечного гласного -ї осуществилась с гласным - $a$, и таким образом тюркское слово стало древнерусским существительным женского рода. Об этом свидетельствуют древнерусские письменные данные: др.-рус. (1486 г.) камка 'шелковая цветная ткань с узорами' (СРЕЗнЕВСКИй 1: 1186-1187); камка (XV-XVI вв. 1472 г.) 'шелковая цветная узорчатая ткань' (ДРС 7: 48).
} 
РАдлов 1899 = РАдлов В. В. Опьт словаря тюркских наречий. Т. 2. Санкт-Петербург, 1899.

РКПкСл = БАСКАКОВ Н. А. (ред.) Русско-каракалпакский словарь. Москва, 1967.

Соколов 1834 = Соколов П. Общчии ичерковно-славянско-русский словарь, или собрание речений. Ч. 1-2. Санкт-Петербург, 1834.

СРЕЗНЕВСКИЙ = СРЕЗНЕВСКИЙ И. И. Материаль для словаря древнерусского языка по письменным памятникам. Т. 1-3. Санкт-Петербург, 1893-1912.

ТРСл = ОСмАНОВ М. М. Татарско-русский словарь. Москва, 1966.

ТуркмРСл = БАСКАКОВ Н. А., КАРРЫЕВ Б. А., ХАМЗАЕВ М. Я. (ред.) Туркменско-русский словарь. Москва, 1968.

ТурРСл = МустАФАЕВ Э. М., СТАРОТОВ Л. Н. (ред.) Туреияко-русский словарь. Москва, 1977.

УРСл = АКОБиРОв С. Ф., МихАЙЛов Г. Н. (ред.) Узбекско-русский словарь. Ташкент, 1988.

ФАСМЕР = ФАСМЕР Макс: Этимологический словарь русского языка. Т. 1-4. Москва, 1986-1987.

ШиповА 1976 = ШиповА Е. Н. Словарь тюркизмов в русском языке. Алма-Ата, 1976.

AKALiN 2011 = AKALiN Ş. (haz.) Türkçe sözlük. Ankara, 2011.

BAWDEN 1996 = BAWDEN Ch. Mongolian-English Dictionary. London-New York, 1996.

Clauson 1972 = Clauson G. An Etymological Dictionary of Pre-Thirteenth-Century Turkish. Oxford, 1972.

KARA 1998 = KARA György: Mongol-magyar kéziszótár. Budapest, 1998.

LESSING 1973 = Lessing F. (ed.) Mongolian-English Dictionary. Bloomington, 1973.

VASMER 1953 = VASMER M. Russisches etymologisches Wörterbuch. Band 1. Heidelberg, 1953.

\section{Литература}

ДоБРодомов-РомановА 1970 = ДоБРодомов И. Г., РомАновА Г. Я. (ред.) Библиография основной отечественной литературы по изучению ориентализмов в восточнославянских языках. В кн.: МЕнгЕС К. Г. Восточные элементы в «Слове о полку Игореве». Ленинград, 1970. 211-238.

ЗАлизняк 2004 = ЗАлизняк А. А. Древненовгородский диалект. Издание 2-е, переработанное с учетом материала находок 1995-2004 гг. Москва, 2004.

КурБАТОВ 1995 = КурБАТОВ Х. Р. Орфоэпия. В кн.: ЗАКИЕВ М. З. (ред.) Татарская грамматика. Т. 1. Казань, 1995. 120-129.

МЕНГЕС 1970 = МЕНГЕС К. Г. Восточные элементы в «Слове о полку Игореве». Ленинград, 1970.

ТумАшЕВА 1989 = ТумАшЕВА Д. Г. Перебой гласных и формирование вокализма кыпчакских языков. В кн.: Сравнительно-историческое изучение языков разных семей. Москва, 1989. 5-18.

Янин 2008 = Янин В. Л. Очерки истории средневекового Новгорода. Москва, 2008.

AgYagÁsi 2010 = AgYagÁsı Klára: Loanwords as data in historical linguistics. An areal linguistic study. In: AgYAGÁsı Klára (ed.): Data in Historical Linguistics. (Sprachtheorie und germanistische Linguistik 20.2.) Münster, 2010. 197-222.

AgYAgÁSi 2016 = AgYAgÁsı Klára: On some oriental elements in Old Novgorodian and other Old Russian dialects. Acta Orientalia Hung. 69 (2016): 391-396. 
DOERFER 1967 = DOERFER G. Türkische und mongolische Elemente im Neupersischen. Unter besonderer Berücksichtigung älterer neupersischer Geschichtsquellen, vor allem der Mongolen- und Timuridenzeit. Bd. 3. Wiesbaden, 1967.

KovÁcs 2016 = KovÁcs Kornél: Некоторые уникальные названия текстильных материалов в древненовгородском диалекте. Slavica 45. Debrecen, 2016. 23-34.

Pelliot 1959 = Pelliot P. Notes on Marco Polo. Vol. 1. (Ouvrage posthume, publié sous les auspices de l'Academie des Inscriptions et Belles Lettres et avec le Concours du Centre National de la Recherche Scientifique.) Paris, 1959. 145-150.

RACHMATI 1932 = RACHMATI G. R. Zur Heilkunde der Uiguren 2. Berlin, 1932.

RÓNA-TAS 1982 = RÓNA-TAS András: Loan-words of ultimate Middle Mongolian origin in Chuvash. In: RónA-TAS András (ed.): Studies in Chuvash Etymology 1. (Studia UraloAltaica 17.) Szeged, 1982. 66-134.

RÓNA-TAS 1986 = RónA-TAS András: Tocharische Elemente in den altaischen Sprachen? In: RónA-TAS András: Language and History. Contributions to Comparative Altaistics. (Studia Uralo-Altaica 25.) Szeged, 1986. 69-74.

RónA-TAS 1996 = RónA-TAS András: A honfoglaló magyar nép. Budapest, 1996.

RÓNA-TAS-BERTA 2011 = RónA-TAS András, BERTA Árpád: West Old Turkic. Turkic Loanwords in Hungarian. Vol. 1. Wiesbaden, 2011.

VÁSÁRY 2007 = VÁSÁRY István: Turks, Tatars and Russians in the 13th-16th Centuries. Aldershot, 2007.

VÁSÁRY 2015 = VÁSÁRY István: The Tatar Factor in the Formation of Muscovy's Political Culture. In: Amitai R., Biran M. (eds.) Nomads as Agents of Cultural Change. The Mongols and Their Predecessors. Honolulu, 2015. 252-270.

Werner 1984 = Werner J. Der Grabfund von Malaja Perěšepina und Kuvrat, Kagan der Bulgaren. München, 1984. 